\title{
Brief Report \\ Sex Differences in Response to Listening to Self-Selected Music during Repeated High-Intensity Sprint Exercise
}

\author{
Kendall J. Rhoads ${ }^{\dagger}$, Sierra R. Sosa ${ }^{\dagger}$, Rebecca R. Rogers, Thomas J. Kopec (D) and Christopher G. Ballmann *(D) \\ Department of Kinesiology, Samford University, 800 Lakeshore Drive, Birmingham, AL 35229, USA; \\ krhoads@samford.edu (K.J.R.); ssosa@samford.edu (S.R.S.); rrogers1@samford.edu (R.R.R.); \\ tkopec@samford.edu (T.J.K.) \\ * Correspondence: cballman@samford.edu \\ + Indicates authors contributed equally.
}

Citation: Rhoads, K.J.; Sosa, S.R.; Rogers, R.R.; Kopec, T.J.; Ballmann, C.G. Sex Differences in Response to Listening to Self-Selected Music during Repeated High-Intensity Sprint Exercise. Sexes 2021, 2, 60-68. https://doi.org/10.3390/sexes 2010005

Received: 29 December 2020

Accepted: 15 January 2021

Published: 18 January 2021

Publisher's Note: MDPI stays neutral with regard to jurisdictional claims in published maps and institutional affiliations.

Copyright: (C) 2021 by the authors Licensee MDPI, Basel, Switzerland. This article is an open access article distributed under the terms and conditions of the Creative Commons Attribution (CC BY) license (https:// creativecommons.org/licenses/by/ $4.0 /)$.

\begin{abstract}
The purpose of this study was to examine possible sex differences in high-intensity exercise performance, fatigue, and motivational responses to exercise while listening to music. Physically active males and females (ages 18-24) were recruited to participate. Participants completed two separate repeated sprint exercise trials each with a different condition: (1) no music (NM) (2) selfselected music (SSM). During each trial, participants completed $3 \times 15 \mathrm{~s}$ Wingate anaerobic tests (WAnTs) while listening to NM or SSM separated by 2 min of active recovery. Following each WAnT, rate of perceived exertion (RPE) and motivation to exercise were assessed. Relative power output, fatigue index, RPE, and motivation were analyzed. There were no significant sex differences for relative power between music conditions $(p=0.228)$. Fatigue index was significantly lower in females while listening to SSM $(p=0.032)$ versus NM while no differences were observed for males $(p=0.246)$. RPE was lower while listening to SSM versus NM in females $(p=0.020)$, but not for males ( $p=0.277)$. Lastly, motivation to exercise increased in the SSM condition versus NM in females $(p=0.006)$ but not in males $(p=0.090)$. Results indicate that listening to SSM music did not result in superior anaerobic performance in either sex, but females responded more favorably to subjective outcomes (i.e., RPE and motivation) while listening to SSM, which may have in turn influenced indices of fatigue during the tests. These results suggest that females may respond more positively than males to exercise-induced fatigue while listening to SSM music during repeated bouts of high-intensity exercise.
\end{abstract}

Keywords: Wingate; anaerobic; motivation; perceived exertion; fatigue index

\section{Introduction}

Listening to music during exercise can serve as an external motivator and has been frequently reported to induce ergogenic effects in multiple forms of exercise [1-3]. While underlying mediators to improvements in performance are still being delineated, simultaneous changes in physiological (e.g., heart rate and neuromuscular activation), psychological (e.g., motivation and enjoyment), and psychophysiological (e.g., perceived exertion and arousal) factors likely work synergistically to improve performance [3-5]. Music may be particularly important during high-intensity exercise as it may serve as a distraction from effort and discomfort during challenging physical tasks [1]. Evidence has suggested that previously mentioned performance factors may manifest themselves differently during exercise in a sex-dependent manner [6,7]. However, few investigations to date have studied possible differences in high-intensity exercise response while listening to music between males and females. Given that music is generally used by both sexes during training [8], knowledge of possible differences in benefits from music could help to optimize training and performance for both males and females.

Sex-dependent differences in high-intensity exercise responses have been widely observed although much debate remains $[7,9,10]$. Females have been shown to a higher 
fatigue tolerance than males during isokinetic testing [11]. Furthermore, females have been shown to be more resistant to performance losses during repeated sprints compared to males suggesting a higher resistance to fatigue [10]. Precise physiological underpinnings for sex differences in fatigue remain elusive, but may be due to neuromuscular and metabolic differences [12]. Sex differences in exercise responses may also be psychological as previous evidence has shown that males and females are motivated to exercise differently [13]. Still others have shown relatively minimal sex differences to exercise responses or fatigue $[9,14]$. Collectively, disparities in findings suggest a need for future research and little is known how external factors such as music may alter aforementioned sex differences in exercise responses.

There is limited evidence directly comparing high-intensity exercise response differences between males and females while listening to music [15-17]. In competitive soccer players, listening to warm-up music has been shown to improve subsequent sprint times only in female athletes [16]. Furthermore, females listening to preferred music improved endurance running performance compared to nonpreferred, while no benefit was observed in males [18]. However, others have refuted these findings suggesting sex differences in exercise performance while listening to music are minimal [15,17]. Rasterio et al. showed that listening to preferred music does not alter anaerobic threshold or improve time to effort regardless of sex [17]. Cutrufello et al. showed that males and females improved power output while listening to music similarly during a single Wingate anaerobic test (WAnT) [15]. Given the lack of consensus of findings, more investigation to describe possible sex-specific differences in exercise response while listening to music is warranted. While previous studies have suggested that females fatigue less during exercise and are more extrinsically motivated $[10,13]$, we are unaware of any investigations to date that have accounted for these factors. Furthermore, many previous investigations use mixed sex sampling where male and female outcomes are pooled for analysis, which eliminates possibility of direct comparison. Thus, the purpose of this brief report was to investigate sex-specific differences in physical performance, fatigue, and motivation during repeated high-intensity sprint exercise while listening to self-selected music.

\section{Materials and Methods}

\subsection{Participants}

Sixteen physically active young adults (males $(M)=8$; females $(F)=8$ ) participated [10]. Descriptive characteristics of participants can be seen in Table 1. Physically active was defined as accruing at least $150 \mathrm{~min} /$ week of moderate intensity physical activity [19]. To screen for exercise safety, a physical activity readiness questionnaire (PARQ) was used prior to commencement of any exercise protocols [19]. Exclusion criteria included: presence of lower body injury in the past 6 months, cardiovascular disease, metabolic disease, neuromuscular disease, and any form of hearing impairment. Prior to each visit, participants were asked to refrain from caffeine, nicotine, and alcohol for a minimum of $12 \mathrm{~h}$ and vigorous physical activity for $24 \mathrm{~h}$.

Table 1. Descriptive characteristics of participants. Data are presented as mean $\pm \mathrm{SD}$.

\begin{tabular}{ccc}
\hline Characteristic & Males $(\boldsymbol{n}=\mathbf{8})$ & Females $(\boldsymbol{n}=\mathbf{8})$ \\
\hline Age (years) & $21.6 \pm 1.7$ & $20.1 \pm 1.1$ \\
Height $(\mathrm{cm})$ & $183.0 \pm 6.6$ & $166.2 \pm 5.4$ \\
Body mass $(\mathrm{kg})$ & $89.3 \pm 16.2$ & $61.9 \pm 6.4$ \\
\hline
\end{tabular}

\subsection{Protocol}

Participants completed two different randomized visits with counterbalanced conditions: no music (NM) and self-selected music (SSM). To determine self-selected music choice, participants were asked to choose any song of any genre as long as the tempo was $>120 \mathrm{bpm}[20,21]$. Music was played through headphones on a single device with a 
standardized volume for all participants $[1,20]$. The song was played on loop to ensure music played throughout the entirety of the exercise bout. During the NM condition, participants were not listening to music and were only exposed to room noise.

After anthropometric measures were recorded, participants completed a 3-min standardized warm-up at 50 watts on a mechanically braked cycle ergometer (Monark, Varberg, Sweden). For the repeated supramaximal tests, participants completed $3 \times 15 \mathrm{~s}$ Wingate Anaerobic Tests (WAnT) as previously described [1,22]. Briefly, participants completed the WAnTs on an electronically braked cycle ergometer (Velotron, RacerMate Inc., Seattle, WA, USA). Seat height was standardized between visits. At the beginning of each WAnT, participants pedaled for $20 \mathrm{~s}$ against an unloaded resistance that was followed by a 10-s lead-in phase to allow participants to achieve maximal pedal rate. Following the end of the lead-in phase, resistance was immediately applied at 7.5\% of the participant's body mass and they pedaled as hard and as fast as possible for $15 \mathrm{~s}$. Participants then completed 2 additional WAnTs for a total of 3 supramaximal tests with separation of 2 min of active recovery.

Relative power output and fatigue index measures were calculated over each $15 \mathrm{~s}$ WAnT period via Velotron Software (v4 1.0.6 Velotron, RacerMate Inc., Seattle, WA, USA). Specifically, for fatigue index, the following calculation was used: ((Watts peak $_{-}$ Watts minimum)/15 s WAnT duration). Motivation to exercise and rate of perceived exertion (RPE) were measured after each WAnT. To measure motivation, a 0-100 visual analog scale (VAS) was utilized [2,20]. Briefly, participants were instructed to mark on a $100 \mathrm{~mm}$ line how motivated they felt to exercise where 0 was "zero motivation" and 100 was "extremely motivated." To determine subjective perception of how hard the exercise was, RPE was measured using a 1-10 scale where 1 was "extremely easy" and 10 was "completely exhausted." All visits were separated by a minimum of $48 \mathrm{~h}$.

\subsection{Data Analysis}

All data were analyzed using Jamovi software (Version 0.9, Jamovi, Sydney, Australia). For all variables, a $2 \times 2 \times 3$ (sex $\times$ condition $\times$ test) repeated measures ANOVA was used to detect differences. A Tukey post hoc analysis was used to detect differences in pairwise comparisons. Estimates of effect sizes for main effects were calculated using eta-squared $\left(\eta^{2}\right)$. All data are presented as mean \pm standard deviation (SD). Significance was set at $p \leq 0.05$ a priori.

\section{Results}

\subsection{Relative Power Output and Fatigue Index}

Test-to-test (WAnT1, WAnT2, and WAnT3) relative power output and fatigue index variables can be seen in Figure 1. For relative power (w/ kg) (Figure 1a), there was a main effect for test $\left(p=0.003 ; \eta^{2}=0.053\right)$ but not for condition $\left(p=0.228 ; \eta^{2}=0.009\right)$ or sex $\left(p=0.520 ; \eta^{2}=0.022\right)$. There were no interactions for condition $\times \operatorname{sex}\left(p=0.384 ; \eta^{2}=0.005\right)$, test $\times \operatorname{sex}\left(p=0.799 ; \eta^{2}=0.002\right)$, condition $\times$ test $\left(p=0.258 ; \eta^{2}=0.002\right)$, or condition $\times \operatorname{sex} \times$ test $\left(p=0.888 ; \eta^{2}<0.001\right)$. Pairwise comparisons showed that relative power during WAnT3 was significantly lower than WAnT1 $(p<0.001)$. For fatigue index $(w / s)$ (Figure $1 b)$, there was a main effect for test $\left(p=0.002 ; \eta^{2}=0.019\right)$, condition $(p=0.035$; $\left.\eta^{2}=0.033\right)$, and sex $\left(p<0.001 ; \eta^{2}=0.472\right)$. No interactions for condition $\times \operatorname{sex}(p=0.509$; $\left.\eta^{2}=0.002\right)$, test $\times \operatorname{sex}\left(p=0.791 ; \eta^{2}=0.001\right)$, condition $\times$ test $\left(p=0.639 ; \eta^{2}=0.003\right)$, or condition $\times$ sex $\times$ test $\left(p=0.564 ; \eta^{2}=0.003\right)$ existed. 


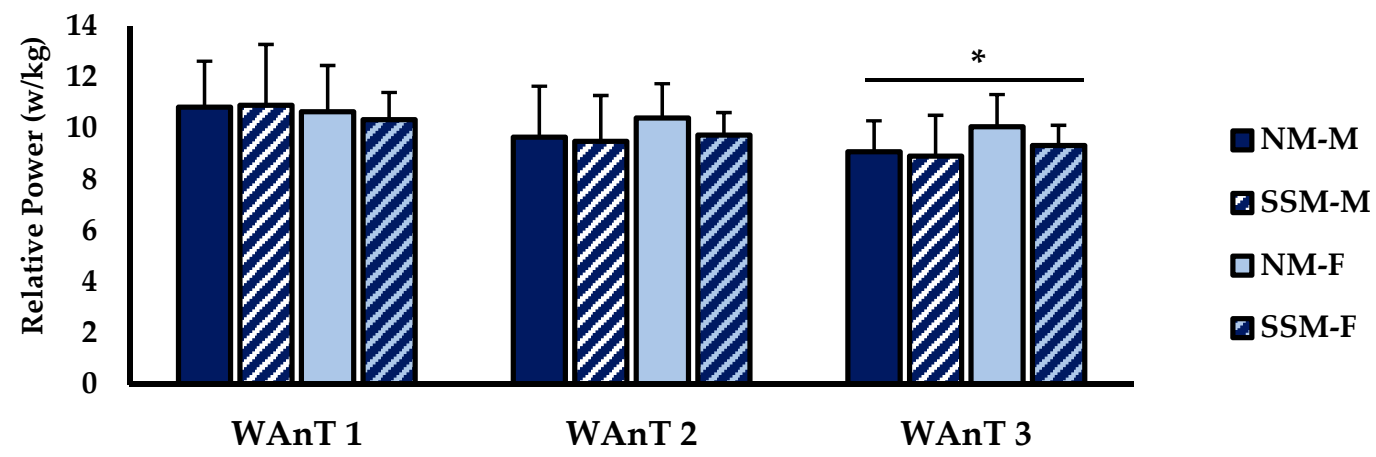

(a)

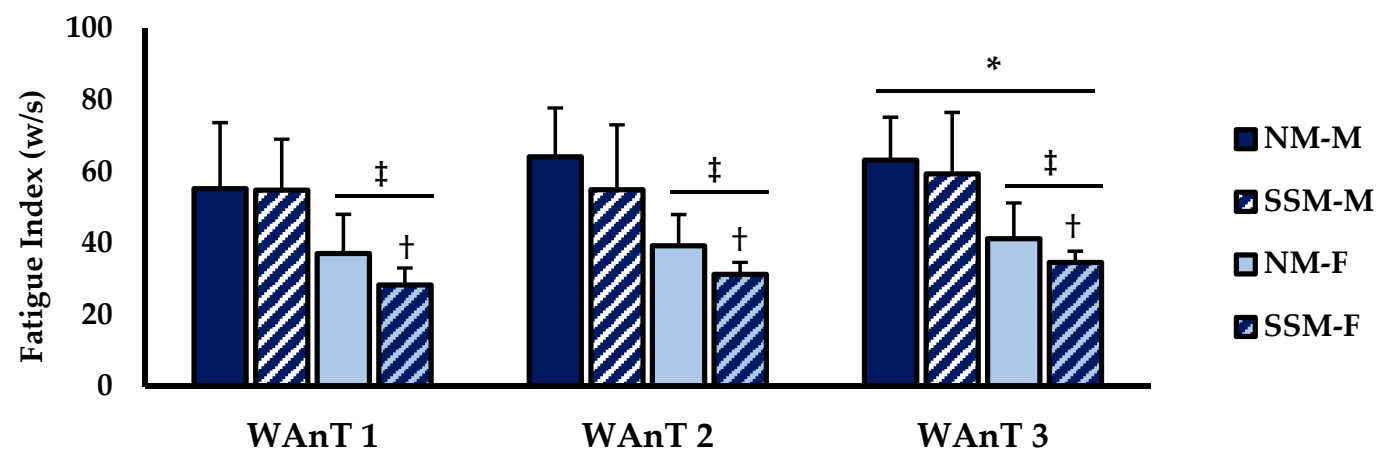

(b)

Figure 1. Anaerobic performance and physical fatigue measures for Wingate 1 (WAnT1), Wingate 2 (WAnT2), and Wingate 3 (WAnT3), for males (M) and females (F) during no music (NM) and self-selected music (SSM) conditions. (a) Relative power (watts/kilogram) and (b) fatigue index (watts/second). Data are presented as mean \pm SD. * indicates significantly different from WAnT 1 (main effect) $(p \leq 0.05)$. $\ddagger$ indicates significantly different from male (main effect) $(p \leq 0.05)$. † indicates significantly different from NM $(p \leq 0.05)$.

\subsection{Rate of Perceived Exertion (RPE) and Subjective Motivation}

Test-to-test (WAnT1, WAnT2, and WAnT3) RPE and subjective motivation are shown in Figure 2. For RPE (1-10 scale) (Figure 2a), there was a main effect for test $(p<0.001$; $\left.\eta^{2}=0.148\right)$ and sex $\left(p=0.049 ; \eta^{2}=0.098\right)$. However, no main effect existed for condition $\left(p=0.757 ; \eta^{2}=0.001\right)$. There was a significant interaction for condition $\times \operatorname{sex}(p=0.013$; $\left.\eta^{2}=0.028\right)$ but not test $\times \operatorname{sex}\left(p=0.126 ; \eta^{2}=0.022\right)$, condition $\times$ test $\left(p=0.068 ; \eta^{2}=0.013\right)$, or condition $\times$ sex $\times$ test $\left(p=0.349 ; \eta^{2}=0.005\right)$. Pairwise comparisons showed that RPE during NM-M for WAnT1 was significantly lower than NM-M WAnT2 $(p=0.027)$ and NM-M WAnT3 $(p<0.001)$. Furthermore, SSM-M for WAnT1 was significantly lower than SSM-M WAnT2 $(p=0.027)$ and WAnT3 $(p=0.002)$. During WAnT2 $(p=0.046)$ and WAnT3 $(p=0.040)$, RPE for SSM-F was significantly lower than NM-F. Motivation (1-100 scale) is displayed in Figure $2 b$. There was a main effect for test $\left(p=0.027 ; \eta^{2}=0.26\right)$ and condition $\left(p=0.021 ; \eta^{2}=0.105\right)$ but not sex $\left(p=0.197 ; \eta^{2}=0.049\right)$. There were no interactions for condition $\times \operatorname{sex}\left(p=0.573 ; \eta^{2}=0.005\right)$, condition $\times$ test $\left(p=0.283 ; \eta^{2}=0.009\right)$, or condition $\times$ sex $\times$ test $\left(p=0.526 ; \eta^{2}=0.005\right)$. There was an interaction for test $\times$ sex $\left(p=0.044 ; \eta^{2}=0.022\right)$. Pairwise comparisons showed that for WAnT1, motivation for SSM-F was significantly higher than SSM-M $(p=0.031)$. Motivation during SSM-M was significantly higher during WAnT1 than WAnT3 $(p=0.030)$. Furthermore, motivation for SSM-F was significantly higher than NM-F for WAnT1 $(p=0.049)$, WAnT2 $(p=0.050)$, and WAnT3 $(p=0.032)$. 


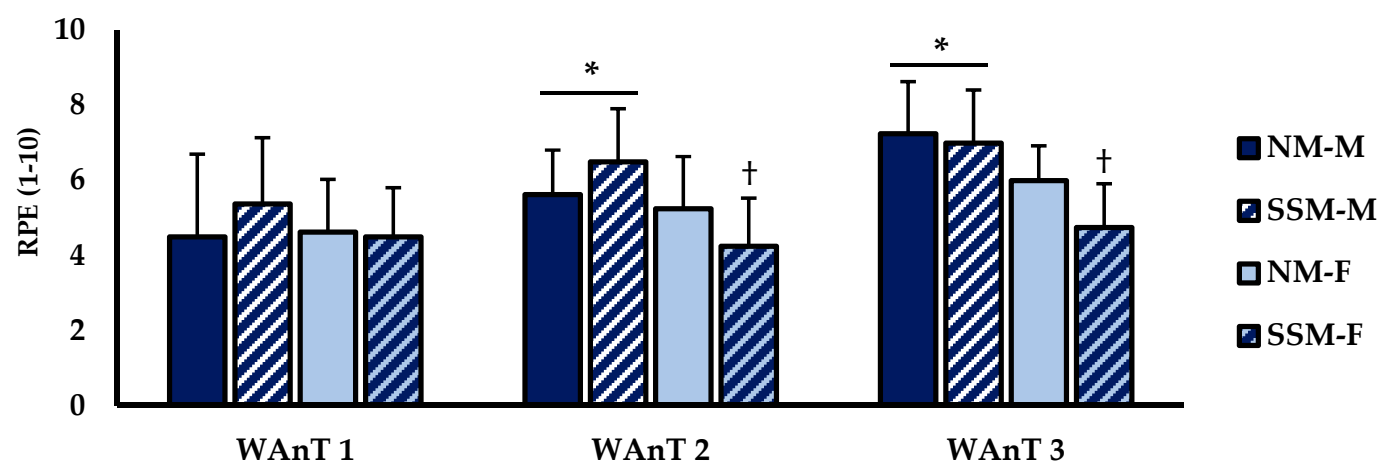

(a)

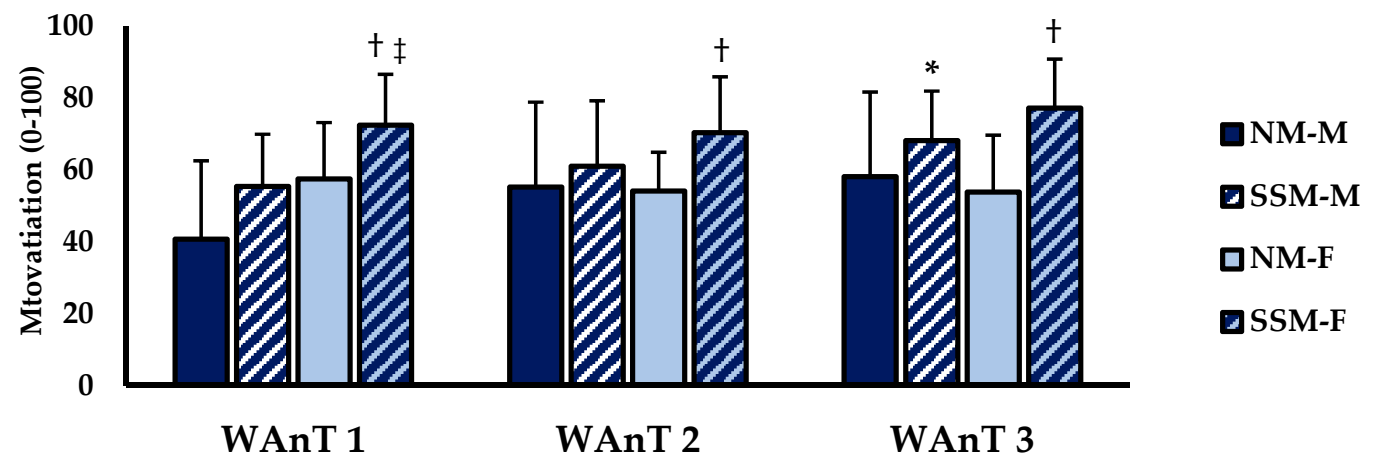

(b)

Figure 2. Rate of perceived exertion (RPE) and motivation measures for Wingate 1 (WAnT1), Wingate 2 (WAnT2), and Wingate 3 (WAnT3), for males (M) and females (F) during no music (NM) and self-selected music (SSM) conditions. (a) RPE (1-10 scale). (b) subjective motivation (0-100 scale) as measured via visual analog scale. Data are presented as mean \pm SD. * indicates significantly different from WAnT $1(p \leq 0.05)$. $\ddagger$ indicates significantly different from corresponding male condition $(p \leq 0.05)$. + indicates significantly different from NM-F $(p \leq 0.05)$.

\section{Discussion}

There has been numerous reports of physiological sex differences in exercise response, which generally show that females may be more resistant to fatigue [7,12]. Music is commonly used as an ergogenic aid in both sexes but there have been some reports showing that males and females may respond to music differently during exercise $[8,16]$. However, little to no evidence exists on whether there are sex differences in repeated anaerobic exercise performance, fatigue, and exercise motivation. Thus, this brief report addressed this and investigated the effects of SSM on repeated supramaximal WAnT performance. Findings show that there were no differences in relative power between sexes while listening to SSM. Independent of condition, females had lower fatigue index values compared to males. Listening to SSM decreased fatigue index compared to no music but this effect was only present in females. Only females reported lower RPE values during the SSM condition versus NM showing lower levels of subjective fatigue. SSM increased motivation to exercise compared to NM solely in females. Overall, results suggest that males did not respond favorably to SSM during repeated WAnTs. However, females listening to SSM showed improvements in physical and subjective fatigue measures, which occurred concurrently with increased motivation. While this brief report was not able to delineate distinct mechanisms responsible for sex differences in exercise responses with SSM, these data present new and interesting findings on how males and females may benefit differently from listening to music during exercise.

Currently, no changes in relative power were seen for males or females regardless of condition. This suggests that SSM may not improve the ability to increase power output during repeated WAnTs, which supports previous findings $[1,23]$. In males, previous evi- 
dence has shown that listening to preferred music does not increase relative power using similar WAnT testing protocols [1]. Pujol et al. showed similar findings with no changes in power output during WAnTs while listening to music [23]. The lack of performance changes may in part be due to a lack of pacing during the exercise as WAnTs involve pedaling as fast as possible. The rhythmic nature of music allows individuals to synchronize their movement to the beat and tempo of the song, which may be beneficial during exercise. Indeed, auditory-motor synchronization has been shown to increase time to exhaustion during running in a mixed sex sample despite no differences in RPE [24]. Bacon et al. also showed increased exercise efficiency in males during cycling with movement synchronized to music tempo [25]. Since participants were concerned with pedaling as fast as they could, the ability synchronize movement to music was likely lost thus negating any potential pacing benefit to performance. Furthermore, the high-intensity nature of the WAnTs may have also led to no differences between sexes due to similar contractile performance. Indeed, sex differences in neuromuscular activation have been shown to be lost at higher percentages of maximum voluntary contraction [26]. A recent meta-analysis reported that listening to music has limited ergogenic effects during WAnTs although other psychophysiological benefits may occur [27]. Collectively the current data, in support with previous evidence, suggest that there may be limited benefits of listening to SSM during supramaximal exercise and this is apparent in both males and females.

Fatigue index, which denotes the total loss of power output during the test, was significantly lower in females compared to males regardless of condition. Present findings support possible sex differences in fatigue during exercise, which have been established by previous groups $[10,28]$. Male field hockey players have been shown to have higher fatigue indexes during running sprints compared to female players [28]. Laurent et al. also reported that females were more resistant to losses in sprint performance compared to males [10]. While the current study did not elucidate physiological mechanisms, previous work has shown that glycogen usage during high-intensity exercise and markers of highenergy phosphate deamination are lower in females possibly indicating more efficient substrate utilization [7]. Interestingly, listening to SSM potentiated reductions in fatigue index in females, but not in males. This was also true for subjective fatigue as measured through RPE. In part, this may be due to greater dissociation from discomfort and exertion during exercise while listening to music. Music has been well established to serve as an external distraction capable of decreasing sensations of fatigue $[1,29]$. Potteiger et al. reported lower local (i.e., legs) and overall (i.e., full body) RPE during cycling in a mixed sex sample [29]. Others have also shown lower RPE values during repeated WAnTs while listening to preferred music albeit in males [1]. Thus, the dissociation may have allowed females to maintain power output over the test and decreased the feelings of exertion to a greater extent than males. Females have been shown to exhibit higher emotional sensitivity to musical stimuli compared to males [30]. While the reasons for differences are not fully clear, prior studies have shown that brain activation responses while listening to music are different between males and females [31]. Although speculative, females may have had differences in brain activation during exercise while listening to SSM resulting in a greater ability to disassociate from physical and psychophysiological fatigue perception. Bolstering this, Carlson et al. showed that females listening to music had differing prefrontal cortex activation and superior ability to divert attention from negative thoughts compared to males [32]. However, no indices of neural activation or brain activity were measured, and future investigations are needed to determine if neural responses during high-intensity exercise while listening to music differ between males and females. Lower indices of fatigue in females while listening to music occurred concomitantly with increases in exercise motivation. Music has been well established to increase motivation during strenuous exercise and physical activity $[1,2,20]$. Furthermore, increases in exercise motivation have also been linked with lower RPE [1,20]. In relation to fatigue index, increases in motivation while listening to music could have led to females being better able to maintain their power output over the test duration thus possibly decreasing fatigue 
index. Supporting sex differences in motivation, previous studies have shown that females tend to be more extrinsically motivated versus males who are more intrinsically motivated with exercise [13]. Since music is an external motivator, disparities in motivation to exercise between males and females may be due to female propensity to feel more motivated to the external music stimulus. Study of the specific aspects of music, which may underlie these motivational changes, is warranted.

While the current brief report presents new findings on sex differences in exercise responses while listening to music, there were several limitations. First, the sample size was relatively young, physically active, and small, which may not be fully representative of all populations. While other studies in this topic area have used equal or similar sample sizes [10], the need for larger representation of the general population is warranted in order to further increase generalizability of results. While many previous investigations supporting lower exercise fatigue in females measured the physiological underpinnings of sex differences $[6,7]$, the current study did not decipher physiological determinants of fatigue leaving these explanations primarily speculative. Since females are grossly understudied in exercise and performance-based research [33], detailing physiological responses to exercise while listening to music are of a dire need in females particularly. Lastly, there are several intrinsic characteristics of music (i.e., genre, lyrics, time signature, etc.), which could not be accounted for in the study design leaving the need for further studies to independently control for these aspects.

\section{Conclusions}

In conclusion, neither males nor females improved relative power output while listening to SSM. However, females showed lower indices of fatigue and increased motivation to exercise when listening to SSM, while males showed no apparent benefit in these areas. From a practical standpoint, females looking to attenuate fatigue and increase motivation during strenuous exercise may use SSM as an ergogenic aid. In the long term, this may help females to optimize training in efforts to reach peak physical capabilities. While males did not see an apparent benefit from SSM in current investigation, it is worth noting that current findings were bases off average performances of each group. Responses to music are highly individualized and some individuals may benefit outside of average responses. Thus, we recommend that athletes and coaches should consider using group analysis to make decisions but understand that individualized approaches are still likely warranted to help each athlete reach peak performance. Follow-up studies using larger sample sizes should elucidate how individual music responses and preferences influence performance differently.

Author Contributions: Conceptualization, K.J.R., S.R.S., T.J.K., and C.G.B.; data curation, K.J.R., S.R.S., and R.R.R.; formal analysis, R.R.R. and C.G.B.; investigation K.J.R., S.R.S., R.R.R., T.J.K., and C.G.B.; methodology, K.J.R., S.R.S., T.J.K., and C.G.B.; project administration, C.G.B.; supervision, R.R.R., T.J.K., and C.G.B.; visualization, K.J.R. and S.R.S.; writing-original draft, K.J.R., S.R.S., and C.G.B.; writing-review and editing, R.R.R. and C.G.B. All authors have read and agreed to the published version of the manuscript.

Funding: This research received no external funding.

Institutional Review Board Statement: All experimental procedures were conducted in accordance with the Declaration of Helsinki and approved by the Samford University Institutional Review Board (EXPD-HP-20-SUM-4).

Informed Consent Statement: Informed consent was obtained from all participants involved in the study prior to data collection.

Data Availability Statement: The data for the current study are available within this manuscript.

Conflicts of Interest: The authors declare no conflict of interest. 


\section{References}

1. Ballmann, C.G.; Maynard, D.J.; Lafoon, Z.N.; Marshall, M.R.; Williams, T.D.; Rogers, R.R. Effects of Listening to Preferred versus Non-Preferred Music on Repeated Wingate Anaerobic Test Performance. Sports 2019, 7, 185. [CrossRef] [PubMed]

2. Ballmann, C.G.; McCullum, M.J.; Rogers, R.R.; Marshall, M.M.; Williams, T.D. Effects of Preferred vs. Nonpreferred Music on Resistance Exercise Performance. J. Strength Cond. Res. 2018. [CrossRef]

3. Terry, P.C.; Karageorghis, C.I.; Curran, M.L.; Martin, O.V.; Parsons-Smith, R.L. Effects of music in exercise and sport: A meta-analytic review. Psychol. Bull. 2020, 146, 91. [CrossRef] [PubMed]

4. Carmichael, K.E.; Marshall, D.N.; Roche, B.M.; Olson, R.L. Effects of music on arousal, affect, and mood following moderateintensity cycling. In Proceedings of the International Journal of Exercise Science: Conference Proceedings, Austin, TX, USA, 23 February 2018; p. 91.

5. Stork, M.J.; Kwan, M.Y.; Gibala, M.J.; Martin, K.G. Music enhances performance and perceived enjoyment of sprint interval exercise. Med. Sci. Sports Exerc. 2015, 47, 1052-1060. [CrossRef] [PubMed]

6. Häkkinen, K. Neuromuscular fatigue and recovery in male and female athletes during heavy resistance exercise. Int. J. Sports Med. 1993, 14, 53-59. [CrossRef]

7. Esbjornsson-Liljedahl, M.; Bodin, K.; Jansson, E. Smaller muscle ATP reduction in women than in men by repeated bouts of sprint exercise. J. Appl. Physiol. 2002, 93, 1075-1083. [CrossRef]

8. Hallett, R.; Lamont, A. How do gym members engage with music during exercise? Qual. Res. Sport Exerc. Health 2015, 7, 411-427. [CrossRef]

9. Sayers, S.P.; Clarkson, P.M. Force recovery after eccentric exercise in males and females. Eur. J. Appl. Physiol. 2001, 84, 122-126. [CrossRef]

10. Laurent, C.; Green, J.; Bishop, P.; Sjökvist, J.; Schumacker, R.; Richardson, M.; Curtner-Smith, M. Effect of gender on fatigue and recovery following maximal intensity repeated sprint performance. J. Sports Med. Phys. Fit. 2010, 50, $243-253$.

11. Gentil, P.; Campos, M.H.; Soares, S.; Costa, G.D.C.T.; Paoli, A.; Bianco, A.; Bottaro, M. Comparison of elbow flexor isokinetic peak torque and fatigue index between men and women of different training level. Eur. J. Transl. Myol. 2017, 27, 7070. [CrossRef]

12. Temesi, J.; Arnal, P.J.; Rupp, T.; Féasson, L.; Cartier, R.; Gergelé, L.; Verges, S.; Martin, V.; Millet, G.Y. Are females more resistant to extreme neuromuscular fatigue. Med. Sci. Sports Exerc. 2015, 47, 1372-1382. [CrossRef] [PubMed]

13. Egli, T.; Bland, H.W.; Melton, B.F.; Czech, D.R. Influence of age, sex, and race on college students' exercise motivation of physical activity. J. Am. Coll. Health 2011, 59, 399-406. [CrossRef] [PubMed]

14. Perez-Gomez, J.; Rodriguez, G.V.; Ara, I.; Olmedillas, H.; Chavarren, J.; González-Henriquez, J.J.; Dorado, C.; Calbet, J.A. Role of muscle mass on sprint performance: Gender differences? Eur. J. Appl. Physiol. 2008, 102, 685-694. [CrossRef] [PubMed]

15. Cutrufello, P.T.; Benson, B.A.; Landram, M.J. The effect of music on anaerobic exercise performance and muscular endurance. J. Sports Med. Phys. Fit. 2019, 60, 486-492. [CrossRef]

16. Tounsi, M.; Jaafar, H.; Aloui, A.; Tabka, Z.; Trabelsi, Y. Effect of listening to music on repeated-sprint performance and affective load in young male and female soccer players. Sport Sci. Health 2019, 15, 337-342. [CrossRef]

17. Rasteiro, F.M.; Messias, L.H.D.; Scariot, P.P.M.; Cruz, J.P.; Cetein, R.L.; Gobatto, C.A.; Manchado-Gobatto, F.B. Effects of preferred music on physiological responses, perceived exertion, and anaerobic threshold determination in an incremental running test on both sexes. PLOS ONE 2020, 15, e0237310. [CrossRef]

18. Cole, Z.; Maeda, H. Effects of listening to preferential music on sex differences in endurance running performance. Percept. Mot. Ski. 2015, 121, 390-398. [CrossRef]

19. Liguori, G.; American College of Sports Medicine (ACSM). ACSM's Guidelines for Exercise Testing and Prescription; Lippincott Williams \& Wilkins: Philadelphia, PA, USA, 2020.

20. Karow, M.C.; Rogers, R.R.; Pederson, J.A.; Williams, T.D.; Marshall, M.R.; Ballmann, C.G. Effects of Preferred and Nonpreferred Warm-Up Music on Exercise Performance. Percept. Mot. Ski. 2020, 127, 912-924. [CrossRef]

21. Ballmann, C.G.; Cook, G.D.; Hester, Z.T.; Kopec, T.J.; Williams, T.D.; Rogers, R.R. Effects of Preferred and Non-Preferred Warm-Up Music on Resistance Exercise Performance. J. Funct. Morphol. Kinesiol. 2021, 6, 3. [CrossRef]

22. Ballmann, C.G.; Maze, S.B.; Wells, A.C.; Marshall, M.M.; Rogers, R.R. Effects of short-term Rhodiola Rosea (Golden Root Extract) supplementation on anaerobic exercise performance. J. Sports Sci. 2019, 37, 998-1003. [CrossRef]

23. Pujol, T.J.; Langenfeld, M.E. Influence of music on Wingate Anaerobic Test performance. Percept. Mot. Ski. 1999, 88, 292-296. [CrossRef]

24. Bood, R.J.; Nijssen, M.; Van Der Kamp, J.; Roerdink, M. The power of auditory-motor synchronization in sports: Enhancing running performance by coupling cadence with the right beats. PLoS ONE 2013, 8, e70758. [CrossRef] [PubMed]

25. Bacon, C.; Myers, T.; Karageorghis, C. Effect of music-movement synchrony on exercise oxygen consumption. J. Sports Med. Phys. Fit. 2012, 52, 359.

26. Yoon, T.; Schlinder Delap, B.; Griffith, E.E.; Hunter, S.K. Mechanisms of fatigue differ after low-and high-force fatiguing contractions in men and women. Muscle Nerve Off. J. Am. Assoc. Electrodiagn. Med. 2007, 36, 515-524. [CrossRef] [PubMed]

27. Castañeda-Babarro, A.; Marqués-Jiménez, D.; Calleja-González, J.; Viribay, A.; León-Guereño, P.; Mielgo-Ayuso, J. Effect of listening to music on Wingate anaerobic test performance. A systematic review and meta-analysis. Int. J. Environ. Res. Public Health 2020, 17, 4564. [CrossRef] [PubMed]

28. Hanjabam, B.; Kailashiya, J. Gender difference in fatigue index and its related physiology. Indian J. Physiol. Pharm. 2015, 59, 170-174.

29. Potteiger, J.A.; Schroeder, J.M.; Goff, K.L. Influence of music on ratings of perceived exertion during 20 minutes of moderate intensity exercise. Percept. Mot. Ski. 2000, 91, 848-854. [CrossRef] 
30. Nater, U.M.; Abbruzzese, E.; Krebs, M.; Ehlert, U. Sex differences in emotional and psychophysiological responses to musical stimuli. Int. J. Psychophysiol. 2006, 62, 300-308. [CrossRef]

31. Koelsch, S.; Maess, B.; Grossmann, T.; Friederici, A.D. Electric brain responses reveal gender differences in music processing. NeuroReport 2003, 14, 709-713. [CrossRef]

32. Carlson, E.; Saarikallio, S.; Toiviainen, P.; Bogert, B.; Kliuchko, M.; Brattico, E. Maladaptive and adaptive emotion regulation through music: A behavioral and neuroimaging study of males and females. Front. Hum. Neurosci. 2015, 9, 466. [CrossRef]

33. Costello, J.T.; Bieuzen, F.; Bleakley, C.M. Where are all the female participants in Sports and Exercise Medicine research? Eur. J. Sport Sci. 2014, 14, 847-851. [PubMed] 